\title{
Presacralhydatid Cyst: An Exceptional Presentation
}

\author{
Sebastián Barber-Millet*, Salvador Pous-Serrano, Javier Maupoey-Ibáñez, \\ Marta Trallero-Anoro, Erick Montilla-Navarro, Rosana Palasí-Jiménez \\ Department of Surgery, La Fe Hospital, Valencia, Spain \\ Email: s.barbermillet@gmail.com
}

Received 22 June 2014; revised 22 July 2014; accepted 20 August 2014

Copyright (C) 2014 by authors and Scientific Research Publishing Inc.

This work is licensed under the Creative Commons Attribution International License (CC BY). http://creativecommons.org/licenses/by/4.0/

(c) (i) Open Access

\begin{abstract}
Introduction: Hydatidosis is caused by the larvae of the cestode Echinococcus granulosus. Liver and lung are the most frequent locations. We report a rare case of a primary hydatid disease location in pre-sacral space. Clinic case: A 64-year-old male patient who consulted due to right gluteal area pain radiating to outer side of the right leg. Physical examination showed a positive Lasègue with hypoesthesia in right L4 L5 S1 territories, with loss of strength in S1. The x-ray showed L3 vertebral wedging and a lumbar lordosis rectification. Laboratory tests and tumor markers were negative. Endorectal ultrasonography described a multilobulatedpresacral cystic tumor. Magnetic resonance imaging (MRI) showed a $16 \times 10 \times 11 \mathrm{~cm}$ retro rectal mass. Due to uncertain diagnosis, surgery was performed, with previous albendazol administration and surgical field protection with $20 \%$ hypertonic saline solution. Combined approach (laparotomy + Kraske incision) was realized. Postoperative course was uneventful. The patient remained asymptomatic 36 months after surgery. Summary: Presacralhydatid cysts are rare entities, but must be considered in differential diagnosis of space-occupying lesions in presacral region. Surgery is treatment of choice, and medical treatment may be useful to prevent recurrences.
\end{abstract}

\section{Keywords}

Presacralhydatid Cyst, Echinococcosis, Sciatica, Combined Surgical Approach

\section{Introduction}

Hydatidosis or hydatid cyst is a disease caused by the larvae of the cestode Echinococcus granulosus, whose definitive host is the dog. The man, who is an intermediate host, is accidentally inserted into the cycle of the para-

${ }^{*}$ Corresponding author.

How to cite this paper: Barber-Millet, S., Pous-Serrano, S., Maupoey-Ibáñez, J., Trallero-Anoro, M., Montilla-Navarro, E. and Palasí-Jiménez, R. (2014) Presacralhydatid Cyst. An Exceptional Presentation. Surgical Science, 5, 384-388. 
site. That happens from eating contaminated food, and prevents the finalization of its reproductive cycle, as the larvae have no chance of transmission [1]. It is the most common zoonosis in several countries in South America, Asia, and the Mediterranean area.

Liver and lung are the most frequent locations. However, damages are described in most organs and body regions, after crossing the parasite liver and lung filter [2].

We report the case of a primary hydatid disease location in presacral space.

\section{Clinic Case}

A 64-year-old male patient with hypertension, diabetes and right hip prosthesis, who consulted due to right gluteal area pain radiating to outer side of the right leg, accompanied by urinary incontinence.

Physical examination showed a positive Lasègue with hypoesthesia in right L4 L5 S1 territories, with loss of strength in S1. No skin lesions or peripheral edema were seen, and there was persistence of distal pulses. With digital rectal examination (DRE), a large tumor compressing rectal ampulla was observed.

The x-ray showed L3 vertebral wedging and a lumbar lordosis rectification. Laboratory tests showed only erythrocyte sedimentation rate of $76 \mathrm{~mm} / \mathrm{h}$. Tumor markers were negative.

Endorectal ultrasonography described a multilobulatedpresacral cystic tumor (Figure 1).

Magnetic resonance imaging (MRI) showed a $16 \times 10 \times 11 \mathrm{~cm}$ multicysticpresacral-retrorectal mass, ranging from S1 to S5, with anterior displacement of the rectosigmoid junction. It also occupied the space between the gluteal muscles and the posterior aspect of the acetabulum.

According to the images, following differential diagnosis was proposed: development cyst, neural lineage multicystic tumor, chordoma, teratoma, and hydatid cyst.

MRI findings were confirmed by CT. Neural or bone origin of the tumor was considered improbable, as long as no direct invasion was observed. The tumor seemed to be dependent of the rectal wall, compatible with fibrosarcoma or cystadenoma.

Definitive diagnosis could not be established by imaging techniques, so we decided to perform an exploratory laparotomy. Given the uncertain origin of the cyst, preoperative administration of albendazol $400 \mathrm{mg}$ every 12 hours was decided, from two weeks before surgery. Surgical field was protected with compresses soaked with $20 \%$ hypertonic saline solution.

Suprainfraumbilical laparotomy was performed, with parietosigmoid dissection until retrorectalspace was reached. At the beginning of the dissection the cyst broke, and release and dissemination of daughter vesicles into protected field occurred. Dissection of the tumor was finished, and abundant repeated washing with $20 \%$ saline hypertonic solution was performed. We continued with a Kraskepararectal incision to reach the hydatid cavity area, in order to complete debridement. Finally, drainage was placed.

Pathological anatomy revealed a hemorrhagic mass with hyaline walls, tapeworm scolex with lymphoid infiltrates around, confirming the diagnosis of hydatid disease (Figure 2)

Postoperative course was uneventful. Mictional and neurological clinic disappeared.

The patient was followed up for 36 months. He remained asymptomatic. MRI was performed 12 months after

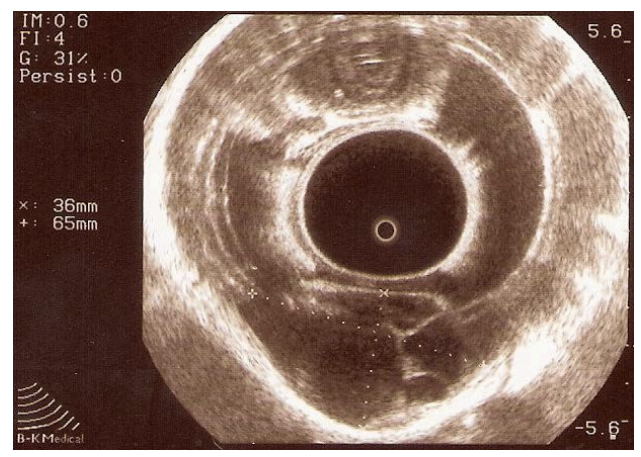

Figure 1. Ultrasound images demonstrated a large, multiloculated lesion, adjacent to the posterior wall of rectum. 


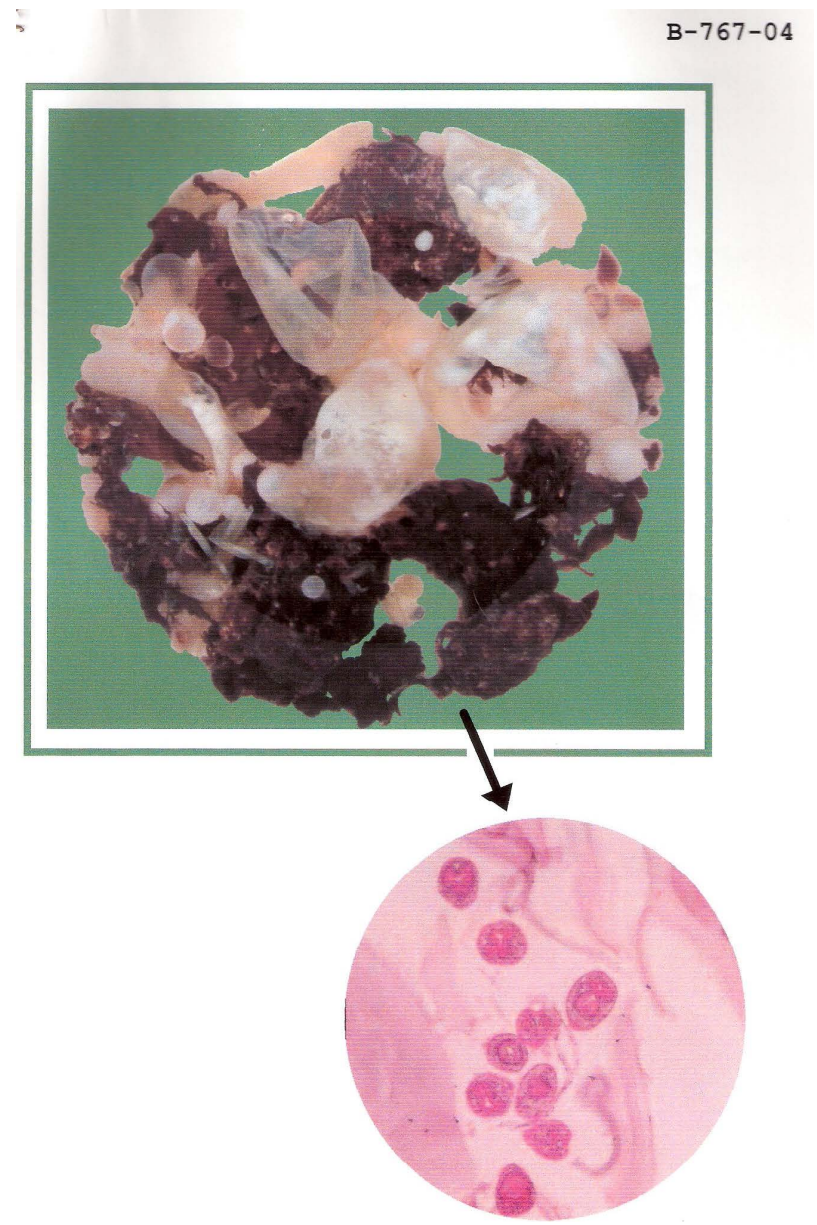

Figure 2. The piece revealed a hemorrhagic mass with hyaline walls, tapeworm scolex with lymphoid infiltrates around.

surgery and showed a cystic collection of 3 small locules in presacral area. This cyst was seen 12 months later in $\mathrm{TC}$ as a $1.5 \mathrm{~cm}$ calcified ring lesion in right sciatic notch.

No changes were detected in the last control the following year, also studied by CT.

The patient received antiparasitic treatment with albendazol and praziquantel up to 6th postoperative month.

\section{Discussion}

The location of hydatid disease elsewhere different from the natural anatomical filters (liver and lung) is rare, even in countries where the disease is endemic [3] [4]. However, it has been diagnosed in almost any region of the body, such as spleen $(0.9 \%-8 \%)$, kidney $(1 \%-4 \%)$, pancreas $(0.25 \%-0.75 \%)$, abdominal wall, thyroid, pharynx, heart, channel marrow, bones, brain, cerebellum... [5]

Migration and final location of the hydatid depends on host immunity, and aggression and filtration capacity of the parasite, which can migrate through the lymphatic and venous system anywhere in the body [6].

The diagnosis of hydatid disease in these exceptional cases requires other techniques in addition to the clinic, because it is usually nonspecific [1]. In most of the cases is related to the compressive nature of the cyst. Depending on the anatomy, it can range from simple tumor, allergic reaction rupture, or secondary infection, to authentic pain syndromes [5] [7]. In case of presacralor retroperitoneal location, the most common clinical presentation are abdominal mass, pain, and, less frequently, compression of organs such as the bladder or rectum [2] [7].

Laboratory studies can help to make the diagnosis. Eosinophilia, common in parasitic diseases, is present in most of the cases of liver and lung. However, according to the literature, this laboratory abnormality is seen only 
in $25 \%$ of the cases of retroperitoneal, presacral, or bone localization, to give some examples [8].

Sensibility of immunology is inversely proportional to the kidnapping of intracystic antigens. Detection of IgG and IgE antibodies by ELISA, immunofluorescence, and intradermal Casoni reaction can confirm the diagnosis. Despite this, there is a high percentage of false negatives, (33\% in some series) [1].

To reach a diagnosis radiography, ultrasound, CT and MRI could be used.

Radiography may show calcification of the cyst wall. A fully calcified cyst is considered inactive [2].

Ultrasound is the gold standard to diagnose both liver and extrahepatic hydatid disease [8]. CT and MRI are used to know the extension of the disease, and alto to control the regression after treatment [4]. Both techniques show multilocular and cystic nature of the tumors [2].

Surgical resection is the treatment of choice, and it must include germinal membrane and pericyst. This attitude is due to the highly destructive behavior of the tumor, so oncologic criteria are used for excision [4]. If this maneuver is not possible due to the proximity of the cyst to vital structures or inaccessible places, the procedure must include partial resection including the germinal membrane.

As in other tumors of retrorectal space, it is important to consider carefully the surgical approach. It is necessary to determine the exact location of the cyst over the sacrum, and its size. The approach should be posterior (intervention of Kraske) in tumors located under S3 with imaging. In these cases, DRE should touch the upper edge of the tumor. In tumors over S3, the approach should be abdominal, or both combined abdominal plus posterior approach [9].

There are different types of surgical approaches. Transperineal and parasacral ones are the most frequent. Other surgical approaches are: transsphincteric, transrectal and intersphincteric [7] [9]. Transabdominal or combined approaches are indicated in large lesions above sacral promontory. It has the advantage of providing a good visualization of the vasculature, innervation, and ureters.

In the literature there are several cases of laparoscopic approach in benign tumors of the retrorectal space. It is described as a safe alternative that provides excellent visualization of pelvic structures, improved postoperative pain, shorter hospital stay, and better cosmetic results. However, there are no long-term series comparing with other strategies [9].

A further medical treatment with albendazol would be desirable to reduce the subsequent risk of disease recurrence [10]. Some surgeons use $20 \%$ hypertonic saline solution after excision of the cyst, in order to prevent recurrence. This maneuver has not shown its utility [11].

\section{Conclusion}

In conclusion, presacralhydatid cysts, as well as all extrahepatic and extrapulmonar ones, are very rare entities, but must be considered in the differential diagnosis of space-occupying lesions in presacral region, especially in endemic regions or if the patient comes from a rural area. Correlation of symptoms with laboratory tests and imaging are required to reach the final diagnosis. Surgery is the treatment of choice, and medical treatment may be useful to prevent recurrences.

\section{Conflict of Interest Statement}

Sebastian Barber-Millet, Salvador Pous-Serrano, Javier Maupoey-Ibañez, Marta Trallero-Anoro, Erick MontillaNavarro, and Rosana Palasí-Jiménez have no conflict of interest.

\section{References}

[1] Oudidi, A. and El Alami, M.N. (2006) Hydatic Cyst of Thyroid Gland. Annales de Chirurgie, 131, 375-378. http://dx.doi.org/10.1016/j.anchir.2006.03.003

[2] Subercaseaux, V.S., Besa, C.C., Burdiles, O.A., Huete, G.A. and Contreras, O.O. (2010) Retroperitoneal Hydatid Cyst: A Common Disease in a Rare Location. Revista Chilena de Infectología, 27, 556-560.

[3] Semlali, S., Nassar, I., Cissé, A., El-Gueddari, F.Z. and Imani, F. (2004) Cervical Hydatid Disease with Retropharyngeal Involvement: A Case Report. Journal de Radiologie, 85, 51-53. http://dx.doi.org/10.1016/S0221-0363(04)97547-6

[4] Tapia, E.O., Vidal, T.A., Bellolio, J.E. and Roa, S.J.C. (2010) Bone Hydatidosis: Report of Five Patients. Revista Médica de Chile, 138, 1414-1421. http://dx.doi.org/10.4067/S0034-98872010001200011 
[5] Tepetes, K., Christodoulidis, G., Spryridakis, M. and Hatzitheofilou, K. (2007) Large Solitary Retroperitoneal Echinococcal Cyst: A Rare Case Report. World Journal of Gastroenterology, 13, 6101-6103. http://dx.doi.org/10.3748/wjg.13.6101

[6] Findikcioglu, A., Kilic, D., Canpolat, T. and Hatipoglu, A. (2007) Primary Hydatid Disease of the Chest Wall. Annals of Thoracic and Cardiovascular Surgery, 13, 203-205.

[7] Maturana, V., Ferrer, M., Rico, M., Rubio, F. and Belda, R. (2009) Presacral Cystic Tumour. Cirugía Española, 85, 60-62.

[8] Hamamci, E.O., Besim, H. and Korkmaz, A. (2004) Unusual Locations of Hydatid Disease and Surgical Approach. ANZ Journal of Surgery, 74, 356-360. http://dx.doi.org/10.1111/j.1445-1433.2004.02981.x

[9] Boscà, A., Pous, S., Artés, M.J., Gómez, F., Granero Castro P. and García-Granero, E. (2012) Tumours of the Retrorectal Space: Management and Outcome of a Heterogeneous Group of Diseases. Colorectal Disease, 14, 1418-1423. http://dx.doi.org/10.1111/j.1463-1318.2012.03016.x

[10] Ozyurtkan, M.O., Koçyiğit, S., Cakmak, M., Ozsoy, I.E. and Balci, A.E. (2009) Case Report: Mediastinal Hydatid Cysts. Türkiye Parazitolojii Dergisi, 33, 179-181.

[11] Senoglu, M., Bulbuloglu, E., Demirpolat, G., Altun, I. and Celik, M. (2009) Combined Anterior and Posterior Approach for Sacral/Retroperitoneal Hydatid Cyst Disease: Case Report. Turkish Neurosurgery, 19, 428-432. 
Scientific Research Publishing (SCIRP) is one of the largest Open Access journal publishers. It is currently publishing more than 200 open access, online, peer-reviewed journals covering a wide range of academic disciplines. SCIRP serves the worldwide academic communities and contributes to the progress and application of science with its publication.

Other selected journals from SCIRP are listed as below. Submit your manuscript to us via either submit@scirp.org or Online Submission Portal.
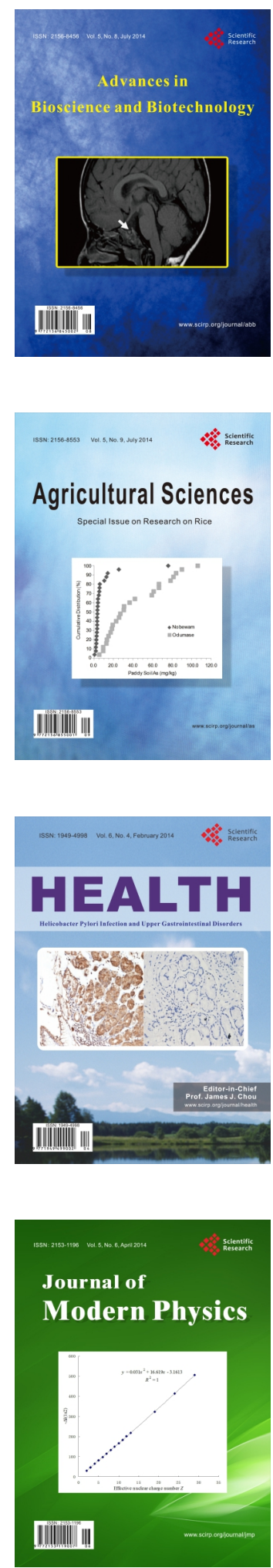
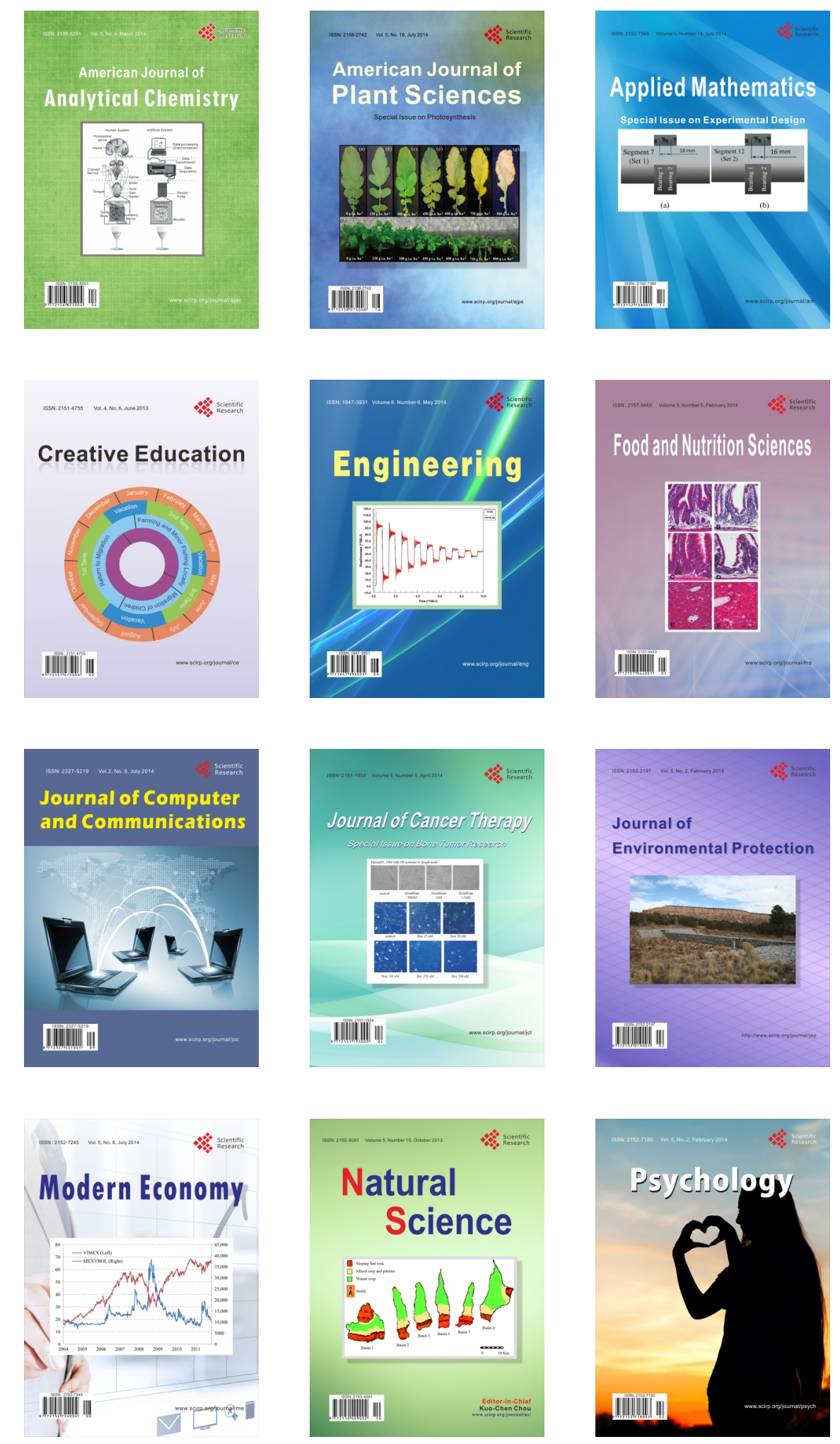